\title{
The Management Information System Research of Ideological and Political Work Based on Workflow
}

\author{
LIU Dai ${ }^{1, a}$ \\ ${ }^{1}$ Ideological and political theory department, Shenyang sport university,110102 \\ a liudai_239@126.com
}

Keywords: Ideological and Political Work; Workflow Technology; Management Information System

\begin{abstract}
To improve students' management level and the efficiency of management is urgently needs to solve the problem. To enhance investment in student management system of the ideological and political work, improve the students' thought political work management informatization level is one of the effective means to improve students' management. By building the student thought political work management system, can let students staff from tedious daily affairs, put more time and energy in the students' ideological education work, and thus improve the efficiency of student management work. In this paper, the design of student work management system based on workflow technology, adopting the popular B/S software architecture system, this paper proposes a simple linear workflow is implemented, which makes the actual work in a wide range of tasks can be a summary of the process of data display, and gives part of the code, this system has achieved good results in practical application.
\end{abstract}

\section{Introduction}

With the development of computer, multimedia and network technology, mankind has entered the information society, information and knowledge plays a more and more important role in contemporary society [1]. In recent years, the ministry of education, according to the needs of national economic and social development, vigorously expand the scale of enrollment, the number of students increased dramatically, thus increasing the difficulty of students' ideological and political work. Therefore, how to improve students' ideological and political work management personnel's work efficiency and achieve the informatization of specification as a whole and distribution management, science, has become the school preferred to solve key problems [2].

Workflow technology in the student work management system there is a widespread lack of interoperability, and support the application of such problems as lack of dynamic capability. Based on workflow technology to realize the event handling matters will automatically transfer to a personal page, no longer need to process the user training, smooth implementation process changes, the user simply focus on processing on the data of their concern. Using the current popular B/S software architecture of the system, the workflow management system based on Web adopts three layer architecture mode, namely the client/application server/database server mode. System architecture and database design are given in this paper, the analysis of the specific business process design, and realize the function of each module, and achieved good effect in practical application.

\section{Basic theory of workflow technology}

"Workflow" is defined by Workflow Management Coalition as all or part of support or automatic processing of the business process by computer. Workflow management system is, in fact, the first by executing the process definition through the computer, and then to support the business process, of course, a business process is a group of special setting. Time to work, management and execution process is to rely on it to support [3].

Workflow management system in practice is generally divided into workflow model, workflow model instantiation and workflow execution. Using the workflow modeling tools to complete business process model is established, the actual business operation process into for the computer 
can simulate processing workflow model, it is the first stage; Secondly, the use of specific business process workflow engine to complete instantiation, deal with transfer for specific business process of workflow relevant data and workflow control data, and provide resources needed for the business process for, this is the second stage; Workflow execution stage mainly to complete the implementation of business process, the key task is to complete the human-computer interaction and the system of internal or external applications call, this is the third stage [4-5]. According to the division of three stages of the workflow, the workflow management system structure can be divided into process design definition function, operation and control functions the interactive interface three levels of function, as shown in figure 1.

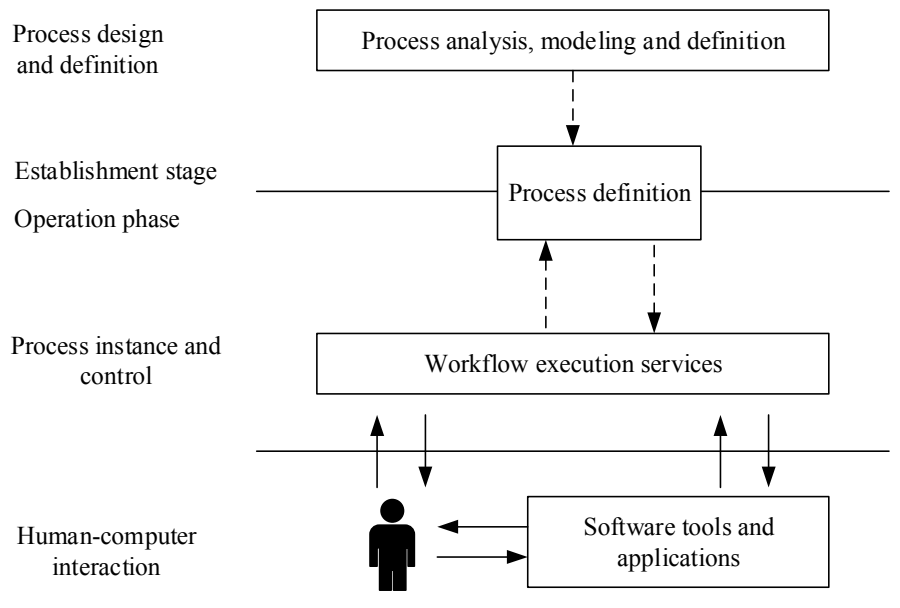

Figure 1.Workflow management system operation process

\section{Structure analysis of workflow running system}

Due to different workflow system have different characteristics, such as operating environment, the development environment is different. To realize interconnection and interoperability of each other, the structure of workflow system to standardize became a necessity. For this workflow management coalition put forward a series of the related rules of the workflow management system, defines the structure of workflow management system and its application, management tools, and with the interfaces between different workflow. Figure 2 is for workflow management system architecture.

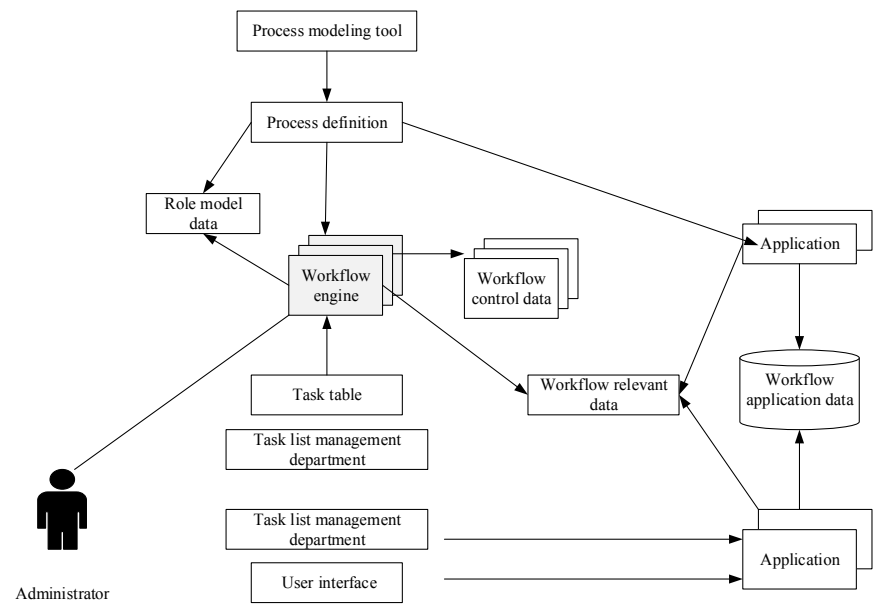

Figure 2.Workflow management system architecture

After completed the process definition model, the generated workflow model controlled by the workflow execution service software for instance creation and its implementation process. Workflow execution service to describe the process of using workflow model initialization, execution of each activity in the process of monitoring and scheduling, when need human 
intervention to complete computer application software and operator interaction [6]. The workflow implementation defined in the model the connection between the business process and reality. This connection by workflow execution service and application software, interaction between operating people. To realize the core functions of the connection is a basic workflow management control software, the workflow engine, responsible for the process to create, delete, scheduling control, application tools and the interaction of human resources. Workflow engine in addition to complete the process to create, delete, the execution and control of the activities, another important function is to complete and application software operating personnel interactions, thus make the whole business activities a run of the whole.

\section{The design of management information system for ideological and political work based on workflow}

Informatization of Ideological and political education is the inevitable trend of development of the information age, but in the implementation process in China due to cognitive and other reasons, many new problems and experience, such as the form, the content of Ideological and political education from the local reality, resulting in "pure technology" and "localization". Students' ideological and political work should management system in digital campus with other systems on the basis of the unified data platform to realize data sharing fully, open data access interfaces for other system.

Java Management Extensions (JMX) is based on Java collection of a series of technical specifications and development tool, is used to solve the problem of distributed system Management and software integration. JMX is a kind of management structure, application programming interfaces, extensible objects and methods of collection, it can be used for different system architecture and network transmission protocol and operating system platform, the development of integrated systems, networks, and the application of network management specification. As shown in figure 3, the JMX architecture is a three layer model, respectively is distributed service layer, broker layer and equipment layer.

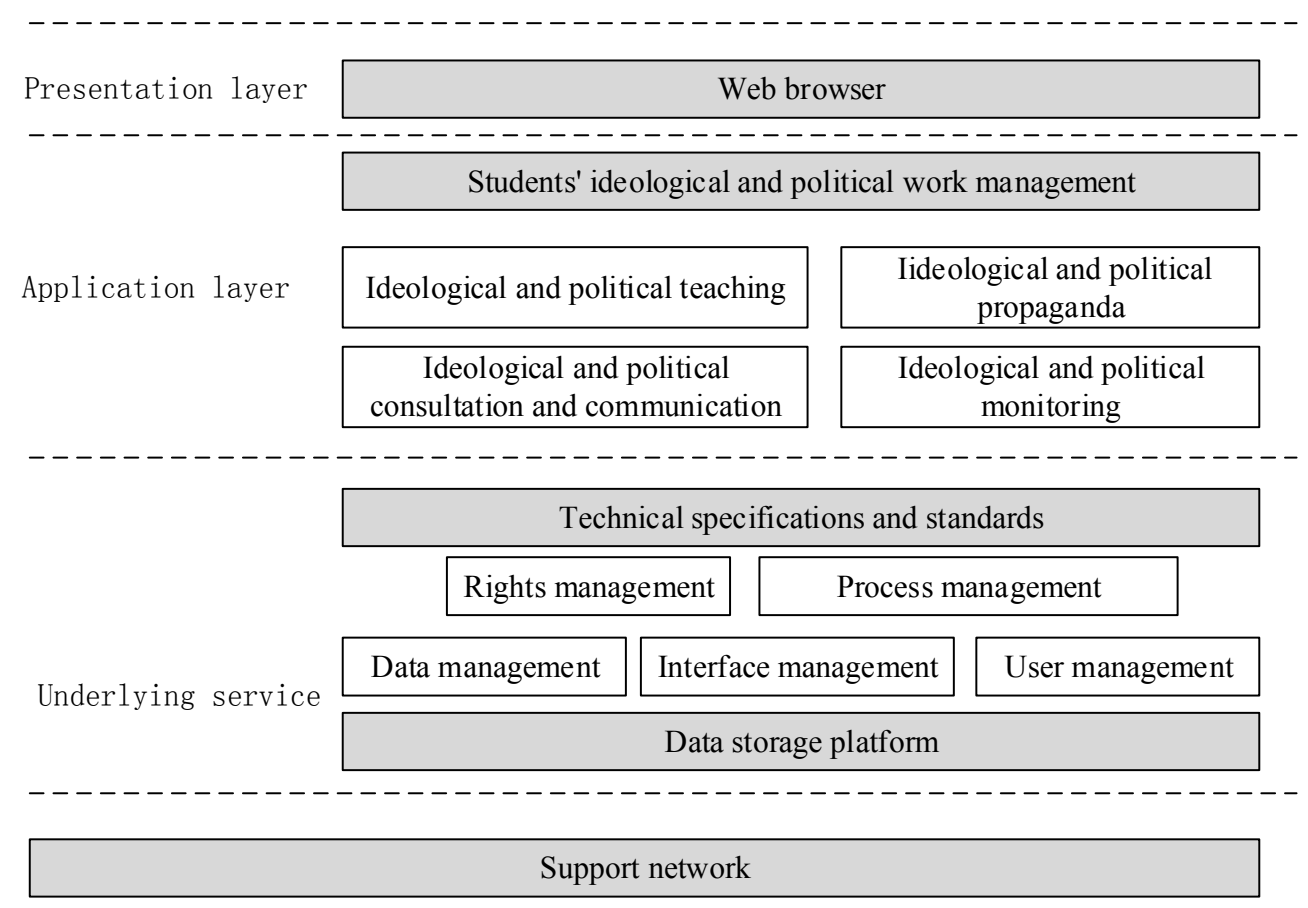

Figure 3. The management information system for ideological and political work based on workflow

Equipment layer provides the JMX specification management resources. A JMX can be source of management is that it can be an application, a device and a service or strategy implementation, managed resources by encapsulated into a Java object conforms to the JMX specification, can be of 
any application management in line with the JMX specification. This combination of three layers, for design and development management scheme implements a complete architecture. JMX also includes a drive into the interface, through the interface, a JMX agent and the management of resources are available to work together with various management model. At the same time, the JMX specification defines a set of general alarm model based on Java event model.

\section{Conclusion}

This article is based on students' ideological and political work management problems as the research object, in view of the problem analysis of the architecture of the system, puts forward the student thought political work the concept of management information system model, and combining the reality of student management, provides theoretical basis for system design. Learning management system basic is currently on the market belongs to the early information collection system, which is by the underlying data acquisition staff input the corresponding data. But often these data is in after work to collect and input, poor real-time data collection, and increase the workload of data acquisition staff. This article from a new perspective to the ideological and political information management system to carry on the design, put forward the model based on workflow management system. The system uses the characteristics of workflow, the use of workflow model abstracts the student management work, and on the computer system to realize the management of students' ideological and political work.

\section{References}

[1] J.M. Xu : Applied Mechanics and Materials. 2014, 687: 2533-2536.

[2] F. JIANG, D. HUANG: The Guide of Science \& Education, 2012, 1: 102.

[3] S. Jaradat, J. Whyte, and R. Luck: Building Research \& Information, 2013, 41(1): 51-59.

[4] W.L. Currie, D.J. Finnegan: Journal of enterprise information management, 2011, 24(2): 146-170.

[5] A. Pithouse, K. Broadhurst, and C. Hall: Journal of Social Work, 2012, 12(2): 158-178. 